\title{
Selective up-regulation of arginase-1 in coronary arteries of diabetic patients
}

\section{Zsolt Bagi *, Attila Feher, Huijuan Dou and Zuzana Broskova}

Vascular Biology Center, Medical College of Georgia, Georgia Regents University, Augusta, GA, USA

Edited by:

Rudolf Lucas, Medical College of Georgia, USA

\section{Reviewed by:}

Prasad V. Katakam, Tulane University

School of Medicine, USA

Pal Pacher, National Institutes of

Health, USA

*Correspondence:

Zsolt Bagi, Vascular Biology Center, Medical College of Georgia, Georgia Regents University, 1120 15th street, Augusta, GA 30912, USA

e-mail: zbagi@gru.edu
Coronary artery disease (CAD) remains the leading cause of death in the Western societies. Diabetes mellitus (DM) is one of the highly prevalent diseases, which remarkably accelerates the development of CAD. Experimental evidence indicates that decreased bioavailability of coronary endothelial nitric oxide (NO) contributes to the development of $\mathrm{CAD}$ in $\mathrm{DM}$. There are recent studies showing that a selective impairment of NO synthesis occurs in coronary arteries of DM patients, which is mainly due to the limited availability of endothelial NO synthase (eNOS) precursor, l-arginine. Importantly, these studies demonstrated that $\mathrm{DM}$, independent of the presence of CAD, leads to selective up-regulation of arginase-1. Arginase-1 seems to play an important role in limiting l-arginine availability in the close proximity of eNOS in vessels of DM patients. This brief review examines recent clinical studies demonstrating the pathological role of vascular arginase-1 in human diabetes. Whether arginase-1, which is crucial in the synthesis of various fundamental polyamines in the body, will represent a potent therapeutic target for prevention of DM-associated CAD is still debated.

Keywords: diabetes mellitus, nitric oxide, arginase, endothelium, coronary artery

\section{DIABETES LEADS TO A REDUCED AVAILABILITY OF NO IN CORONARY ARTERIES}

Diabetes mellitus is associated with an increased incidence of cardiovascular diseases accounting for significant morbidity and mortality in the diabetic population. Coronary artery disease $(\mathrm{CAD})$ is one of the key manifestations of diabetes-associated vascular disease, a pathology, which predisposes diabetic patients to myocardial ischemia. The underlying mechanism(s) of CAD remain incompletely understood in human diabetes, so that effective preventive therapeutic strategies cannot be adopted in diabetic patients.

The coronary flow-reserve, as defined by the ratio of coronary flow under maximal agonist-induced vasodilation to coronary flow under resting conditions, is reduced in diabetic patients, even in the absence of significant stenosis of epicardial coronary arteries (1). Nemes et al. have demonstrated that patients with type 2 diabetes exhibit a reduced coronary flow-reserve (2), a condition, which was found to be associated with increased incidence of future ischemic episode in the heart of diabetic patients (3). Patients with diabetes exhibit endothelial dysfunction, which is characterized by impaired flow- and acetylcholine (ACh)-induced relaxation of brachial artery (4) and forearm resistance vessels (5). Nitenberg et al. have demonstrated that coronary artery dilation is impaired in diabetic patients with angiographically normal coronaries (6). Kaneda et al. performed a study, in which 165 patients underwent intracoronary injection of $\mathrm{ACh}$ and found that diabetes was the strongest predictor for ACh-induced coronary vasospasm (7). This and other studies concluded that diabetes is associated with impaired dilator function of coronary arteries and this is manifested as a reduced vasodilator or even vasoconstrictor responses (8-10).

Previous studies have shown that animals with experimental insulin resistance and diabetes exhibit a reduced NO-mediated, agonist-induced dilation of cerebral, mesenteric, coronary, and skeletal muscle microvessels (11-16). Studies from our laboratory demonstrated that in rodent models of type 2 diabetes coronary arteries exhibit impaired ACh-induced dilation, which is primarily due to the reduced synthesis and/or bioavailability of nitric oxide (NO) (17-20). Katakam et al. have shown that prior to the impaired ACh-mediated vasodilation NO-mediated coronary dilation to insulin is reduced in obese Zucker rats (14). This seems particularly important as insulin and insulin-like growth factor I have shown to promote NO-mediated vasodilation (21).

Oxidative stress occurring in response to hyperglycemia and insulin resistance $(14,22-28)$ is considered to be one of the key factors leading to the reduced NO-dependent vasodilation. To support this scenario, oral administration of the antioxidant vitamin-C prevented the decreases in methacholine-induced brachial artery dilations in patients with diabetes (29). However, other studies failed to detect any beneficial effect of antioxidant therapy in the prevention of diabetes-induced vascular complications $(30,31)$. For instance, vitamin-E supplementation for 8 weeks did not restore the reduced ACh- and bradykinin-induced dilations of brachial arteries in diabetic patients (32). These aforementioned observations raised questions about the efficacy of antioxidant therapy in preventing diabetes-related endothelial dysfunction. To solve the apparent controversy recent studies propose a crucial role for reactive nitrogen species in the development of diabetes-related vascular complications (33). The rate 
constant for the reaction between superoxide anion and NO is three to fivefold greater than the rate of superoxide anion scavenged by superoxide dismutase (34). Given that NO via interacting with superoxide anion generates various reactive nitrogen species, such as the highly reactive peroxynitrite $\left(\mathrm{ONOO}^{-}\right)$. $\mathrm{ONOO}^{-}$has numerous detrimental effects in the cardiovascular system and plays a crucial role in the development of diabetes-induced vascular pathology (33). $\mathrm{ONOO}^{-}$is a powerful oxidizing agent that causes rapid depletion of sulfhydryl groups, causes DNA damage, protein oxidation, and nitration of aromatic amino acid residues in proteins, specifically leading to 3-nitrotyrosin formation (33). Although the endogenous cellular mechanisms to prevent the deleterious effect of $\mathrm{ONOO}^{-}$are not clearly defined recent preclinical studies suggest that a more selective targeting of $\mathrm{ONOO}^{-}$holds considerable potential than the use of conventional antioxidants (35).

\section{DEFICIENCY OF ONOS COFACTORS IN CORONARY ARTERY DISEASE}

It is known that an adequate level of substrates and cofactors for NO synthases, such as L-arginine (36) and tetrahydrobiopterin $\left(\mathrm{BH}_{4}\right)$ is essential for $\mathrm{NO}$ synthesis $(37,38)$. Diabetes has been shown to interfere with the availability of these cofactors thereby leading to a diminished NO synthesis. To provide experimental evidence for this scenario Ihlemann et al. demonstrated that in healthy humans, oral glucose challenge-induced reduction in forearm blood flow is restored by pre-treatment with $\mathrm{BH}_{4}$ (39). Co-infusion of $\mathrm{BH}_{4}$ and the endothelial NO synthase (eNOS) precursor, L-arginine into the forearm of diabetic patients prevented ischemia reperfusion-induced endothelial dysfunction in the brachial artery (40). In isolated coronary arterioles of patients with atherosclerosis Tiefenbacher et al. has shown earlier that in vitro administration of the stable $\mathrm{BH}_{4}$ analog, sepiapterin enhanced dilation in response to agonist (41). In a recent study oral $\mathrm{BH}_{4}$ treatment in patients undergoing heart surgery although augmented total biopterin levels had no significant effects on dilator function of conduit vessels owing to systemic and vascular oxidation of $\mathrm{BH}_{4}$ (42). This latter study warranted the need of further investigations aiming at effectively restoring eNOS cofactor, $\mathrm{BH}_{4}$ levels. Underlying mechanism(s) responsible for the reduced vascular availability of $\mathrm{BH}_{4}$ is not entirely understood in diabetes. It has been shown that $\mathrm{ONOO}^{-}$directly interacts and reduces the level of $\mathrm{BH}_{4}$, as it has greater affinity for $\mathrm{BH}_{4}$ than that of ascorbic acid and glutathione (43). Chen et al. demonstrated that exposure of human eNOS to $\mathrm{ONOO}^{-}$resulted in a dose-dependent loss of activity with a marked destabilization of the eNOS dimer (44). In addition, Ishii et al. has shown that insulin is a potential stimulator of $\mathrm{BH}_{4}$, primarily via activating phosphatidylinositol 3-kinase (45). Due to the apparent lack of insulin action expression and activity of GTP cyclohydrolase-I is reduced in insulin resistance states, which ultimately leads to eNOS uncoupling and diminished NO-mediated dilation of cerebral arteries (46). Whether restoring insulin sensitivity will be associated with "re-coupling" of eNOS has yet to be elucidated.

\section{L-ARGININE TO PREVENT ENDOTHELIAL DYSFUNCTION IN PATIENTS WITH CAD}

$\mathrm{L}$-arginine, the substrate for NO synthase, is the precursor for NO synthesis in the vascular endothelium. Earlier clinical studies indicated that administration of $\mathrm{L}$-arginine may enhance $\mathrm{NO}$ bioavailability and dilate coronary arteries (47). For example, intra-coronary infusion of $\mathrm{L}$-arginine in patients with $\mathrm{CAD}$ attenuated the vasoconstrictor response to intra-coronary ACh and increased coronary blood flow (48). Lerman et al. studied the effect of long-term administration of $\mathrm{L}$-arginine $(9 \mathrm{~g} /$ day) on patients with non-obstructive coronary disease and found a markedly improved coronary vasodilator response to ACh (49). In contrast, in 30 patients with CAD L-arginine therapy while significantly increased L-arginine plasma levels had no effect on NO bioavailability and flow-mediated dilation of brachial artery (50). Moreover, there is another clinical study, which questioned the effectiveness of L-arginine therapy in patients with CAD (50). More importantly, in the Vascular Interaction With Age in Myocardial Infarction (VINTAGE MI) study by Schulman et al. L-arginine supplementation significantly increased mortality in patients with myocardial infraction leading to early termination of the trial with the recommendation that $\mathrm{L}$-arginine supplementation not to be used in patients with myocardial infarction (51). The underlying mechanism responsible for the controversial and harmful effects of $\mathrm{L}$-arginine in this particular patient population remains elusive.

Limited number of studies is available to evaluate the acute and long-term effects of $\mathrm{L}$-arginine treatment in patients with diabetes. In a recent large cohort, involving 2236 patients recruited within the LUdwigshafen RIsk and Cardiovascular Health (LURIC) study, patients with type 2 diabetes had a significantly lower L-arginine availability than patients without diabetes (52). A study has shown that $\mathrm{L}$-arginine treatment ( $8.3 \mathrm{~g}$ /day for 21 days) improved endothelial dilator function and increased insulin sensitivity in patients with type 2 diabetes (53). The authors concluded that L-arginine exerted its beneficial effects through reducing fasting and postprandial glucose levels and normalizing adiponectin/leptin ratio (53). Thus, some evidence indicates that in diabetic patients the level of $\mathrm{L}$-arginine is reduced and administering L-arginine may improve endothelial function. Whether this effect is mediated directly via enhancing the vascular availability of $\mathrm{NO}$ or indirectly via increasing insulin sensitivity has yet to be elucidated. Taken together, it is possible that diabetic patients may benefit from L-arginine supplementation, but several important questions still remain open including the safety and efficacy of L-arginine treatment in diabetic patients with concomitant $\mathrm{CAD}$, especially in those with prior myocardial infarction.

\section{DOES VASCULAR ARGINASE-1 SELECTIVELY UP-REGULATED IN HUMAN DIABETES?}

It is known that the $\mathrm{Km}$ of $\mathrm{NO}$ synthase for $\mathrm{L}$-arginine is about $2.9 \mu \mathrm{M}$. The intracellular concentration of $\mathrm{L}$-arginine ranges from 0.1 to $1.0 \mathrm{mM}$. Given that it seemed intriguing how administration of L-arginine would increase the bioavailability of $\mathrm{NO}-$ the arginine-paradox. To solve this apparent controversy previous studies have shown that up-regulation of arginase, the focal 
enzyme of the urea cycle, via hydrolyzing L-arginine reduces $\mathrm{NO}$ synthesis and, importantly, may contribute to the development of various vascular diseases (36). Detailed pathological role(s) for arginase- 1 and -2 in various disease models as well as the subcellular mechanisms behind is extensively discussed in other review articles in this thematic issue. In this review we examine those few existing clinical studies that focused on altered arginase expression and its vascular consequences in man.

Vascular endothelial cells metabolize L-arginine mainly by arginase, which exists as two distinct isoforms, arginase- 1 and -2 . Arginase-1 is predominantly expressed in the liver and to a much lesser extent in other cell types, such as vascular endothelial cells, whereas expression of arginase-2 is more widespread (54). Circulating arginase-1 level was found significantly higher in patients with heart failure, when compared to controls; and the level of circulating arginase- 1 further increased with the severity of heart failure (significant increase between NYHA I/II and NYHA III/IV groups) (55). When sublingual microcirculation was assessed by dark field intravital microscopy in heart failure patients the authors found that topical administration of the arginase inhibitor, norNOHA increased capillary density, a measure of tissue perfusion, in an NO-dependent manner (55). In patients with essential hypertension Holowatz and Kenney have found an attenuated NOdependent reflex cutaneous vasodilatation, which is enhanced by arginase inhibitors, BEC, and nor-NOHA, but not with L-arginine supplementation (56). These studies provided functional evidence for the role of circulating and also tissue-expressed arginase-1, which interferes with NO-mediated tissue perfusion.

Both arginase- 1 and -2 are expressed in the human heart (54). In a study by Chen et al. right atrial appendage was obtained from 13 patients undergoing heart surgery for coronary artery bypass graft (CABG) with three-vessel CAD and from 13 patients with valve replacement (non-CAD group). In the whole atrial homogenates there was a significantly reduced protein expression of both eNOS and arginase- 1 in patients with CAD. Of note that in this study the CAD group had higher proportion of diabetic patients (11 out of 13), as compared to the control group (3 out of 13). Given that, the individual impact of CAD and diabetes affecting expression of arginase-1 cannot be examined in this study (57). In our recent study (10) small coronary arteries were dissected from the atrial appendage of 21 patients without and 20 patients with diabetes. Protein expression of arginase-1 in small coronary arteries was significantly higher in patients with diabetes. Arginase-1 expression was abundant in endothelial cells and was co-localized with eNOS in coronary vessels of diabetic patients, but not in non-diabetics. We demonstrated that inhibition of arginase, with L-NOHA caused restoration of endothelium-dependent, ACh-induced dilation in coronary arterioles of diabetic patients. Although we proposed an effect of diabetes causing arginase-1 upregulation, it is of note that in the study diabetic patients exhibited a significantly greater proportion of CAD ( 16 out of 20 versus 9 out of 20 patients), therefore the conclusion regarding the selective up-regulation of arginase- 1 in coronary arteries of diabetic patients is severely limited. In a very recent study by Shemyakin et al. the independent impact of diabetes in affecting arginase-1 expression and its functional consequence was evaluated (58).
In 16 patients with $\mathrm{CAD}$ and 16 patients with $\mathrm{CAD}$ and type 2 diabetes endothelium-dependent and endothelium-independent increases in forearm blood flow were assessed during intra-arterial infusion of the arginase inhibitor, nor-NOHA. While forearm blood flow was significantly lower in both CAD and CAD plus diabetes groups, when compared to age-matched control group, nor-NOHA markedly increased blood flow with NO-dependent manner, with a significantly greater extent in patients with concomitant diabetes (58). This key observation provided functional evidence for the selectively up-regulated arginase-1 in diabetic patients, in vivo.

Taken together, limited number of clinical studies suggest a selective up-regulation of arginase-1, which may impair dilator function of conduit and resistance vessels in diabetic patients, independent of the presence of concomitant CAD. Further studies involving higher number of research subjects are needed to assess the independent impact of increased arginase-1 expression on coronary artery responsiveness in diabetes. Moreover, it should be noted that arginase inhibitors, nor-NOHA, and LNOHA used in these studies do not have selectivity toward arginase isoforms (arginase-1 versus arginase-2). Thus, the functional role for arginase-2 in the development of vasomotor dysfunction cannot be entirely excluded. In this regard, a previous study has found that increased expression of arginase-2 leads to decreased NO synthesis in pulmonary endothelial cells of patients with pulmonary arterial hypertension (59). The pathological role of arginase isoforms in diabetes-related coronary microvascular dysfunction also has yet to be elucidated.

\section{POSSIBLE MECHANISIMS LEADING TO SELECTIVE UP-REGULATION OF ARGINASE-1 IN DIABETIC PATIENTS}

The underlying mechanism(s) leading to selective up-regulation of arginase- 1 in coronary arterioles in diabetic patients remains elusive. One obvious possibility is the known action of insulin,

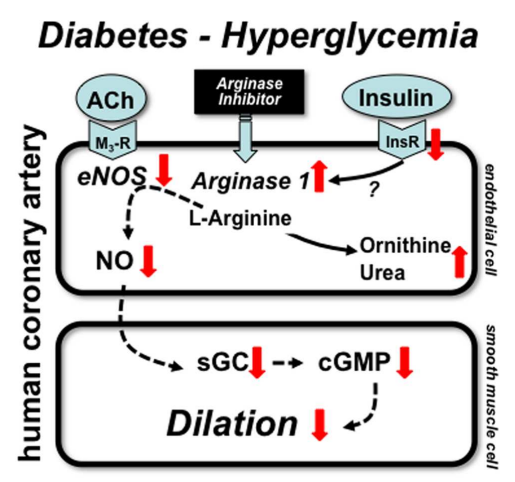

FIGURE 1 | Mechanisms of coronary artery dysfunction in diabetes. Schematic draw demonstrates proposed mechanisms by which diabetes and hyperglycemia lead to up-regulation of arginase-1 resulting in reduced $\mathrm{NO}-$ mediated dilation in human coronary arteries. Alterations in insulin signaling may contribute to arginase up-regulation, which reduces the level of I-arginine and thereby limit NO synthesis. ACh: acetylcholine, $M_{3}-R: M_{3}$ muscarinic receptor, InsR: insulin receptor, sGC: soluble guanylate cyclase, cGMP: cyclic guanosine monophosphate. 
which suppresses expression and activity of enzymes of urea synthesis pathway. Since insulin signaling is impaired in type 2 diabetes (patients likely to exhibit insulin resistance) it is possible that the failure of insulin regulatory action contributes to upregulation of arginase-1. In the clinical setting diabetic patients are on insulin sensitizing and oral anti-diabetic medication or commonly take insulin. For instance, in the study by Shemyakin et al. 31 and $56 \%$ of patients with CAD plus diabetes were on insulin and biguanides/sulfonylureas, respectively (58). In our aforementioned study all patients with diabetes had either anti-diabetic medication or were on insulin (10). Therefore, the effect of insulin resistance and the concomitant action of exogenous insulin is difficult to examine in these investigations. Also, due to the limited number of diabetic patients involved in the aforementioned studies further studies are warranted to ascertain the role of insulin and other pathological factors that could contribute to increased arginase- 1 expression in diabetes. In this context, in a previous elegant study Kashyap et al. found that plasma arginase activity is increased in type 2 diabetic patients with reduced activity of eNOS in the skeletal muscle. Interestingly, these changes were detected without alterations in the plasma protein levels of

\section{REFERENCES}

1. Nitenberg A, Valensi P, Sachs R, Dali M, Aptecar E, Attali JR. Impairment of coronary vascular reserve and ACh-induced coronary vasodilation in diabetic patients with angiographically normal coronary arteries and normal left ventricular systolic function. Diabetes (1993) 42:1017-25. doi:10.2337/diabetes. 42.7.1017

2. Nemes A, Forster T, Lengyel C, Csanady M. Reduced aortic distensibility and coronary flow velocity reserve in diabetes mellitus patients with a negative coronary angiogram. Can $J$ Cardiol (2007) 23:445-50. doi:10.1016/ S0828-282X(07)70782-1

3. Cortigiani L, Rigo F, Gherardi S, Sicari R, Galderisi M, Bovenzi F, et al. Additional prognostic value of coronary flow reserve in diabetic and nondiabetic patients with negative dipyridamole stress echocardiography by wall motion criteria. $J$ Am Coll Cardiol (2007) 50:1354-61. doi:10.1016/j.jacc.2007.06.027

4. Enderle MD, Benda N, Schmuelling RM, Haering HU, Pfohl M. Preserved endothelial function in IDDM patients, but not in NIDDM patients, compared with healthy subjects. Diabetes Care (1998) 21:271-7. doi:10.2337/diacare.21.2. 271

5. Ting $\mathrm{HH}$, Timimi FK, Boles KS, Creager SJ, Ganz P, Creager MA. Vitamin C improves endothelium-dependent vasodilation in patients with non-insulindependent diabetes mellitus. J Clin
Invest (1996) 97:22-8. doi:10.1172/ JCI118394

6. Nitenberg A, Paycha F, Ledoux S, Sachs R, Attali JR, Valensi P. Coronary artery responses to physiological stimuli are improved by deferoxamine but not by L-arginine in non-insulin-dependent diabetic patients with angiographically normal coronary arteries and no other risk factors. Circulation (1998) 97:736-43. doi:10.1161/01.CIR.97. 8.736

7. Kaneda H, Taguchi J, Kuwada Y, Hangaishi M, Aizawa T, Yamakado $\mathrm{M}$, et al. Coronary artery spasm and the polymorphisms of the endothelial nitric oxide synthase gene. Circ J (2006) 70:409-13. doi:10.1253/ circj.70.409

8. Miller FJ Jr, Dellsperger KC, Gutterman DD. Pharmacologic activation of the human coronary microcirculation in vitro: endothelium-dependent dilation and differential responses to acetylcholine. Cardiovasc Res (1998) 38:744-50. doi:10.1016/ S0008-6363(98)00035-2

9. De Vriese AS, Verbeuren TJ, Van De Voorde J, Lameire NH, Vanhoutte PM. Endothelial dysfunction in diabetes. $\mathrm{Br} J$ Pharmacol (2000) 130:963-74. doi:10.1038/sj. bjp.0703393

10. Beleznai T, Feher A, Spielvogel D, Lansman SL, Bagi Z. Arginase 1 contributes to diminished coronary arteriolar dilation in patients with diabetes. Am J Physiol Heart Circ Physiol (2011) 300:H777-83. doi: 10.1152/ajpheart.00831.2010

arginase-1 and -2. Importantly, the increased arginase activation was correlated with the degree of hyperglycemia and was markedly reduced by 4 -h insulin infusion in diabetic patients, but not in nondiabetics (60). This clinical study demonstrated the pathological role for high glucose in inducing, whereas for exogenous insulin in reducing arginase activation. The exact molecular mechanisms remained unclear. The proposed mechanisms by which diabetes and hyperglycemia lead to up-regulation of arginase-1 resulting in reduced NO-mediated dilation in human coronary arteries is depicted in Figure 1.

In summary, recent findings, as highlighted in this brief review underline the need for the investigations exploring the underlying mechanisms responsible for up-regulated arginase in human diabetes. Clinical studies emphasize the importance of those investigations that strive to elucidate the vascular effects of specific arginase inhibitors, including their long-term efficacy and safety in diabetic patients with CAD.

\section{ACKNOWLEDGMENTS}

The authors works are supported by grant R01 HL104126 (Zsolt Bagi) from the National Heart, Lung, and Blood Institute.

11. Frisbee JC, Stepp DW. Impaired NO-dependent dilation of skeletal muscle arterioles in hypertensive diabetic obese Zucker rats. Am J Physiol Heart Circ Physiol (2001) 281:H1304-11

12. Naderali EK, Pickavance LC, Wilding JP, Williams G. Dietinduced endothelial dysfunction in the rat is independent of the degree of increase in total body weight. Clin Sci (Lond) (2001) 100:635-41. doi:10.1042/ CS20000279

13. Erdos B, Miller AW, Busija DW. Impaired endothelium-mediated relaxation in isolated cerebral arteries from insulin-resistant rats. Am J Physiol Heart Circ Physiol (2002) 282:H2060-5.

14. Katakam PV, Tulbert CD, Snipes JA, Erdos B, Miller AW, Busija DW. Impaired insulin-induced vasodilation in small coronary arteries of Zucker obese rats is mediated by reactive oxygen species. Am J Physiol Heart Circ Physiol (2005) 288:H854-60. doi:10.1152/ ajpheart.00715.2004

15. Oltman CL, Richou LL, Davidson EP, Coppey LJ, Lund DD, Yorek MA. Progression of coronary and mesenteric vascular dysfunction in Zucker obese and Zucker diabetic fatty rats. $A m$ J Physiol Heart Circ Physiol (2006) 291:H1780-7. doi:10.1152/ajpheart.01297.2005

16. Katakam PV, Domoki F, Lenti L, Gaspar T, Institoris A, Snipes JA, et al. Cerebrovascular responses to insulin in rats. J Cereb Blood Flow
Metab (2009) 29:1955-67. doi:10. 1038/jcbfm.2009.177

17. Bagi Z, Koller A. Lack of NOmediation of flow-dependent arteriolar dilation in diabetes is restored by sepiapterin. J Vasc Res (2003) 40:47-57. doi:10.1159/000068938

18. Bagi Z, Koller A, Kaley G. Peroxisome proliferator-activated receptor-\{gamma\} activation, by reducing oxidative stress increases NO bioavailability in coronary arterioles in type 2 diabetes. Am J Physiol Heart Circ Physiol (2004) 286:H742-8. doi:10.1152/ajpheart.00718.2003

19. Erdei N, Toth A, Pasztor ET, Papp Z, Edes I, Koller A, et al. High-fat diet-induced reduction in nitric oxide-dependent arteriolar dilation in rats: role of xanthine oxidase-derived superoxide anion. Am J Physiol Heart Circ Physiol (2006) 291:H2107-15. doi:10.1152/ ajpheart.00389.2006

20. Jebelovszki E, Kiraly C, Erdei N, Feher A, Pasztor ET, Rutkai I, et al. High-fat diet-induced obesity leads to increased $\mathrm{NO}$ sensitivity of rat coronary arterioles: role of soluble guanylate cyclase activation. Am J Physiol Heart Circ Physiol (2008) 294:H2558-64. doi:10.1152/ ajpheart.01198.2007

21. Oltman CL, Kane NL, Gutterman DD, Bar RS, Dellsperger KC. Mechanism of coronary vasodilation to insulin and insulin-like growth factor I is dependent on vessel size. Am J Physiol Endocrinol Metab (2000) 279:E176-81. 
22. Ruderman NB, Williamson JR, Brownlee M. Glucose and diabetic vascular disease. FASEB J (1992) 6:2905-14.

23. Bohlen HG, Lash JM. Topical hyperglycemia rapidly suppresses EDRFmediated vasodilation of normal rat arterioles. Am J Physiol (1993) 265:H219-25.

24. Bagi Z, Koller A. Lack of nitric oxide mediation of flow-dependent arteriolar dilation in type I diabetes is restored by sepiapterin. J Vasc Res (2003) 40:47-57. doi:10.1159/ 000068938

25. Bagi Z, Koller A, Kaley G. Superoxide-NO interaction decreases flow- and agonistinduced dilations of coronary arterioles in Type 2 diabetes mellitus. Am J Physiol Heart Circ Physiol (2003) 285:H1404-10.

26. Bagi Z, Koller A, Kaley G. PPARgamma activation, by reducing oxidative stress, increases NO bioavailability in coronary arterioles of mice with Type 2 diabetes. Am J Physiol Heart Circ Physiol (2004) 286:H742-8. doi:10.1152/ajpheart.00718.2003

27. Bagi Z, Toth E, Koller A, Kaley G. Microvascular dysfunction after transient high glucose is caused by superoxide-dependent reduction in the bioavailability of $\mathrm{NO}$ and $\mathrm{BH}(4) . A m$ J Physiol Heart Circ Physiol (2004) 287: H626-33. doi:10.1152/ajpheart. 00074.2004

28. Erdei N, Bagi Z, Edes I, Kaley G, Koller A. H2O2 increases production of constrictor prostaglandins in smooth muscle leading to enhanced arteriolar tone in Type 2 diabetic mice. Am J Physiol Heart Circ Physiol (2007) 292:H649-56. doi:10.1152/ ajpheart.00596.2006

29. Beckman JA, Goldfine AB, Gordon $\mathrm{MB}$, Creager MA. Ascorbate restores endothelium-dependent vasodilation impaired by acute hyperglycemia in humans. Circulation (2001) 103:1618-23. doi:10.1161/ 01.CIR.103.12.1618

30. Marchioli R, Schweiger C, Levantesi G, Tavazzi L, Valagussa F. Antioxidant vitamins and prevention of cardiovascular disease: epidemiological and clinical trial data. Lipids (2001) 36:S5363. doi:10. 1007/s11745-001-0683-y

31. Maxwell S, Greig L. Anti-oxidants a protective role in cardiovascular disease? Expert Opin Pharmacother (2001) 2:1737-50. doi:10. 1517/14656566.2.11.1737

32. Gazis A, White DJ, Page SR, Cockcroft JR. Effect of oral vitamin E (alpha-tocopherol) supplementation on vascular endothelial function in Type 2 diabetes mellitus. Diabet Med (1999) 16:304-11. doi:10.1046/j.14645491.1999.00049.x

33. Pacher P, Beckman JS, Liaudet L. Nitric oxide and peroxynitrite in health and disease. Physiol Rev (2007) 87:315-424. doi:10.1152/ physrev.00029.2006

34. Xu J, Zou MH. Molecular insights and therapeutic targets for diabetic endothelial dysfunction. Circulation (2009) 120:1266-86. doi:10.1161/ CIRCULATIONAHA.108.835223

35. Szabo C, Ischiropoulos H, Radi R. Peroxynitrite: biochemistry, pathophysiology and development of therapeutics. Nat Rev Drug Dis$\operatorname{cov}$ (2007) 6:662-80. doi:10.1038/ $\operatorname{nrd} 2222$

36. Durante W, Johnson FK, Johnson RA. Arginase: a critical regulator of nitric oxide synthesis and vascular function. Clin Exp Pharmacol Physiol (2007) 34:906-11. doi:10.1111/j. 1440-1681.2007.04638.x

37. Vasquez-Vivar J, Kalyanaraman B, Martasek P, Hogg N, Masters BS, Karoui H, et al. Superoxide generation by endothelial nitric oxide synthase: the influence of cofactors. Proc Natl Acad Sci U S A (1998) 95:9220-5. doi:10.1073/pnas.95.16. 9220

38. Thony B, Auerbach G, Blau N. Tetrahydrobiopterin biosynthesis, regeneration and functions. Biochem J (2000) 347:1-16.

39. Ihlemann N, Rask-Madsen C, Perner A, Dominguez H, Hermann $\mathrm{T}$, Kober L, et al. Tetrahydrobiopterin restores endothelial dysfunction induced by an oral glucose challenge in healthy subjects. Am J Physiol Heart Circ Physiol (2003) 285:H875-82.

40. Settergren M, Bohm F, Malmstrom RE, Channon KM, Pernow J. L-arginine and tetrahydrobiopterin protects against ischemia/reperfusion-induced endothelial dysfunction in patients with type 2 diabetes mellitus and coronary artery disease. Atherosclerosis (2009) 204:73-8. doi:10.1016/ j.atherosclerosis.2008.08.034

41. Tiefenbacher CP, Bleeke T, Vahl C, Amann K, Vogt A, Kubler W. Endothelial dysfunction of coronary resistance arteries is improved by tetrahydrobiopterin in atherosclerosis. Circulation (2000) 102:2172-9. doi:10.1161/01.CIR.102.18.2172

42. Cunnington C, Van Assche T, Shirodaria C, Kylintireas I, Lindsay
$\mathrm{AC}$, Lee JM, et al. Systemic and vascular oxidation limits the efficacy of oral tetrahydrobiopterin treatment in patients with coronary artery disease. Circulation (2012) 125:1356-66. doi:10.1161/ CIRCULATIONAHA.111.038919

43. Kuzkaya N, Weissmann N, Harrison DG, Dikalov S. Interactions of peroxynitrite, tetrahydrobiopterin, ascorbic acid, and thiols: implications for uncoupling endothelial nitric-oxide synthase. J Biol Chem (2003) 278:22546-54. doi:10.1074/ jbc.M302227200

44. Chen W, Druhan LJ, Chen CA, Hemann C, Chen YR, Berka V, et al. Peroxynitrite induces destruction of the tetrahydrobiopterin and heme in endothelial nitric oxide synthase: transition from reversible to irreversible enzyme inhibition. Biochemistry (2010) 49:3129-37. doi: 10.1021/bi9016632

45. Ishii M, Shimizu S, Nagai T, Shiota K, Kiuchi Y, Yamamoto T. Stimulation of tetrahydrobiopterin synthesis induced by insulin: possible involvement of phosphatidylinositol 3-kinase. Int J Biochem Cell Bio (2001) 33:65-73.

46. Katakam PV, Snipes JA, Steed MM, Busija DW. Insulin-induced generation of reactive oxygen species and uncoupling of nitric oxide synthase underlie the cerebrovascular insulin resistance in obese rats. J Cereb Blood Flow Metab (2012) 32:792-804. doi:10.1038/ jcbfm.2011.181

47. Gornik HL, Creager MA. Arginine and endothelial and vascular health. JNutr (2004) 134:2880S-7S; discussion $2895 \mathrm{~S}$.

48. Dubois-Rande JL, Zelinsky R, Roudot F, Chabrier PE, Castaigne A, Geschwind $\mathrm{H}$, et al. Effects of infusion of L-arginine into the left anterior descending coronary artery on acetylcholine-induced vasoconstriction of human atheromatous coronary arteries. Am J Cardiol (1992) 70:1269-75. doi:10. 1016/0002-9149(92)90760-V

49. Lerman A, Burnett JC Jr, Higano ST, Mckinley LJ, Holmes DR Jr. Longterm L-arginine supplementation improves small-vessel coronary endothelial function in humans. Circulation (1998) 97:2123-8. doi:10.1161/01.CIR.97.21.2123

50. Blum A, Hathaway L, Mincemoyer R, Schenke WH, Kirby M, Csako $\mathrm{G}$, et al. Oral L-arginine in patients with coronary artery disease on medical management. Circulation (2000) 101:2160-4. doi:10.1161/01. CIR.101.18.2160
51. Schulman SP, Becker LC, Kass DA, Champion HC, Terrin ML, Forman $\mathrm{S}$, et al. L-arginine therapy in acute myocardial infarction: the Vascular Interaction With Age in Myocardial Infarction (VINTAGE MI) randomized clinical trial. JAMA (2006) 295:58-64. doi:10.1001/jama.295.1. 58

52. Sourij H, Meinitzer A, Pilz S, Grammer TB, Winkelmann BR, Boehm $\mathrm{BO}$, et al. Arginine bioavailability ratios are associated with cardiovascular mortality in patients referred to coronary angiography. Atherosclerosis (2011) 218:220-5. doi:10. 1016/j.atherosclerosis.2011.04.041

53. Lucotti P, Setola E, Monti LD, Galluccio E, Costa S, Sandoli EP, et al. Beneficial effects of a long-term oral L-arginine treatment added to a hypocaloric diet and exercise training program in obese, insulin-resistant type 2 diabetic patients. Am J Physiol Endocrinol Metab (2006) 291:E906-12. doi:10.1152/ajpendo. 00002.2006

54. Jenkinson CP, Grody WW, Cederbaum SD. Comparative properties of arginases. Comp Biochem Physiol B Biochem Mol Biol (1996) 114:107-32. doi:10.1016/03050491(95)02138-8

55. Quitter F, Figulla HR, Ferrari M, Pernow J, Jung C. Increased arginase levels in heart failure represent a therapeutic target to rescue microvascular perfusion. Clin Hemorheol Microcirc (2013) 54:75-85. doi:10.3233/CH-2012-1617

56. Holowatz LA, Kenney WL. Upregulation of arginase activity contributes to attenuated reflex cutaneous vasodilatation in hypertensive humans. J Physiol (2007) 581:863-72. doi:10.1113/jphysiol. 2007.128959

57. Chen X, Niroomand F, Liu Z, Zankl A, Katus HA, Jahn L, et al. Expression of nitric oxide related enzymes in coronary heart disease. Basic Res Cardiol (2006) 101:346-53. doi:10.1007/s00395006-0592-5

58. Shemyakin A, Kovamees O, Rafnsson A, Bohm F, Svenarud $\mathrm{P}$, Settergren $\mathrm{M}$, et al. Arginase inhibition improves endothelial function in patients with coronary artery disease and type 2 diabetes mellitus. Circulation (2012) 126:2943-50. doi:10.1161/ CIRCULATIONAHA.112.140335

59. Xu W, Kaneko FT, Zheng S, Comhair SA, Janocha AJ, Goggans T, et al. 
Increased arginase II and decreased NO synthesis in endothelial cells of patients with pulmonary arterial hypertension. FASEB J (2004) 18:1746-8.

60. Kashyap SR, Lara A, Zhang R, Park YM, Defronzo RA. Insulin reduces plasma arginase activity in type 2 diabetic patients. Diabetes Care (2008) 31:134-9. doi:10.2337/dc071198
Conflict of Interest Statement: The authors declare that the research was conducted in the absence of any commercial or financial relationships that could be construed as a potential conflict of interest.

Received: 16 May 2013; paper pending published: 11 July 2013; accepted: 06 September 2013; published online: 26 September 2013.
Citation: Bagi Z, Feher A, Dou $H$ and Broskova $Z$ (2013) Selective up-regulation of arginase-1 in coronary arteries of diabetic patients. Front. Immunol. 4:293. doi: 10.3389/fimmu.2013.00293

This article was submitted to Inflammation, a section of the journal Frontiers in Immunology.

Copyright $\odot 2013$ Bagi, Feher, Dou and Broskova. This is an open-access article distributed under the terms of the Creative Commons Attribution License (CC BY). The use, distribution or reproduction in other forums is permitted, provided the original author(s) or licensor are credited and that the original publication in this journal is cited, in accordance with accepted academic practice. No use, distribution or reproduction is permitted which does not comply with these terms. 